In Crescendo, 2019; 10(2): 411-433

Fecha de recepción: 05/11/2018

Fecha de aceptación: 05/06/2019

\title{
VIVENCIAS DE PÉRDIDA AMBIGUA ANTE LA DESAPARICIÓN FORZADA DE UN INTEGRANTE DE FAMILIA
}

\author{
EXPERIENCES OF AMBIGUOUS LOSS BEFORE THE \\ FORCED DISAPPEARANCE OF A \\ FAMILY MEMBER
}

\begin{abstract}
Paola Alejandra Manríquez-Sánchez', Isabel Cadenas-Guzmán², María de Lourdes Vargas-Garduño ${ }^{3}$, María Elena Rivera-Heredia ${ }^{4}$
\end{abstract}

\section{RESUMEN}

El objetivo de este texto es analizar el impacto emocional y social de la desaparición forzada de una persona, en los integrantes de su familia y sus implicaciones en la dinámica familiar. Se empleó la metodología cualitativa, desde el enfoque fenomenológico, con base en la técnica de la entrevista profunda; el estudio se realizó en Morelia Michoacán, México, con la participación de una familia (madre, padre, 3 hermanas e hija del desaparecido). Los resultados obtenidos a partir del análisis de los discursos de los participantes, permitieron establecer cinco categorías: afrontamiento del duelo, distintos tipos del duelo vivido, malestares orgánicos,

1 Pasante de la Facultad de Psicología de la Universidad Michoacana de San Nicolás de Hidalgo, Morelia, Michoacán México.Correo electrónico: ale.psic.94@gmail.com

2 Pasante de la Facultad de Psicología de la Universidad Michoacana de San Nicolás de Hidalgo, Morelia, Michoacán México.Correo electrónico: isa_598@outlook.es

3 Doctora en Psicología Social, profesora investigadora de la Facultad de Psicología de la Universidad Michoacana de San Nicolás de Hidalgo, Morelia, Michoacán México. Correo electrónico: mlvargas@umich.mx

4 Doctora en Psicología, profesora investigadora de la Facultad de Psicología de la Universidad Michoacana de San Nicolás de Hidalgo, Morelia, Michoacán México. Correo electrónico: dip.umsnh.maelenarivera@gmail.com 
estrategias familiares de recuperación, afrontamiento de la falta de apoyo legal por parte de la familia. Se encontró que la familia atraviesa por una pérdida ambigua, la cual ocasiona confusión, estrés, y que a menudo atormenta su vida cotidiana. Resulta de gran relevancia comprender que con frecuencia los familiares tienen la esperanza de que el desaparecido regrese y que, al no contar con la certeza de su situación actual, se da pie a la vivencia de la pérdida ambigua, por tanto, se dificulta el procesamiento del duelo y la reestructuración del sentido de vida. En el caso de estudio, la desaparición impactó en la dinámica familiar, ya que fortalecieron su vínculo con la intención de aminorar su dolor.

PALABRAS ClAVE: Pérdida ambigua, dinámica familiar, desaparición forzada, duelo.

\section{ABSTRACT}

The objective of this text is to analyze the emotional and social impact of the forced disappearance of an individual, in the members of their family and its implications in family dynamics. The qualitative methodology was used, from the phenomenological approach, based on the technique of the deep interview; the case study was conducted in Morelia, Michoacán, Mexico, with the participation of the subject's family: his mother, his father, three sisters and the daughter of the disappeared. The results obtained from the analysis of the discourse of the participants, allowed the establishment of five categories: coping with grief, different types of grief experienced, organic discomfort, family recovery strategies, coping with the lack of legal support from the family. The result was that the family went through an ambiguous loss, which causes confusion, stress, and often torments their daily lives. It is very important to understand that family members oftentimes have the hope that the disappeared person will return and that if they do not have the certainty of their current situation, the experience of the ambiguous loss will arise, therefore, it is difficult to process the grieving and the restructuring of the meaning of life. In the case study, the disappearance impacted on the family dynamics, since they strengthened their relationships with the intention of reducing their pain.

KEY WORDS: Ambiguous loss, family dynamics, forced disappearance, grief.

\section{INTRODUCCIÓN}

La desaparición forzada de personas es una violación a los derechos humanos y un crimen de lesa humanidad que, por su gravedad, ha atraído el interés de la comunidad internacional y de organismos internacionales que son defensores de derechos humanos, persistiendo en muchos países del mundo, tras haber sido una característica habitual de la segunda mitad del siglo XX que comenzaron a vivirse a gran escala en la Europa ocupada por los nazis en 1941. En el informe de la Convención Internacional para la Protección de Todas las Personas contra las 
Desapariciones Forzadas (ONU, 2006), que México ha ratificado, define la desaparición forzada como:

El arresto, la detención, el secuestro o cualquier otra forma de privación de la libertad que sean obra de agentes del Estado o por personas o grupos de personas que actúan con la autorización, el apoyo o la aquiescencia del Estado, seguida de la negativa a reconocer dicha privación de libertad o del ocultamiento de la suerte o el paradero de la persona desaparecida, sustrayéndola a la protección de la ley (art. 2)

No obstante, difiere del secuestro, en la intención de fondo; puesto que mientras la primera tiene motivos políticos con el único fin de desaparecer a la persona, en el segundo se persigue una ganancia económica, que es generalmente la raíz de todo crimen.

Según datos recabados por el Human Rights Watch (2013) en su informe "México: crisis de desapariciones forzadas", podemos darnos cuenta que hay documentadas alrededor de 250 desapariciones durante el gobierno del expresidente Felipe Calderón Hinojosa, quien ocupó la presidencia entre diciembre de 2006 y diciembre de 2012. Con respecto a dichos datos, podemos destacar que la organización encontró pruebas donde 149 casos fueron sobre desapariciones forzadas, en los que tuvieron participación agentes estatales.

Las estadísticas del Registro Nacional de Datos de Personas Extraviadas o Desaparecidas (RNPED) denotan que casi el 50\% de las desapariciones han tenido lugar entre los años 2012 y 2014 (Procuraduría General de la República, 2015). Por otra parte, el 25 de abril de 2001 es tipificada la desaparición forzada de personas a nivel federal en el artículo 215-A del código penal según información de la Comisión Mexicana de Defensa y Promoción de los Derechos humanos A.C. (2013), no obstante, resultó inadecuado la definición, pues, restringe la autoría del delito únicamente a "servidores públicos", es por ello que partir del día 16 de enero del año 2018 entro en vigor la Ley General de Desaparición forzada de personas, Desaparición Cometida por Particulares y del Sistema Nacional de Búsqueda de Personas en todo el país, con lo cual podrá enjuiciarse a los ejecutores de dichos hechos (Rodríguez, s./f.) $)^{5}$.

5 Para revisar el formato de la nueva ley consultar:

http://www.diputados.gob.mx/LeyesBiblio/pdf/LGMDFP_171117.pdf 
Por otro lado, hasta la fecha no se ha llevado a cabo un análisis sobre la vivencia de las familias que sufren una pérdida de esta índole, a la que teóricos como Boss (2001), denominan "pérdida ambigua" la cual se suscita en este tipo de situaciones como consecuencia de la guerra y la violencia. Por pérdida ambigua, se entiende la ausencia física o psicológica de un individuo, generada por enfermedades, como el Alzheimer, o por desapariciones forzadas o voluntarias, que impiden a los familiares, tener claro si la persona vive o está muerta.

Atravesar por este tipo de pérdida, acarrea una serie de inestabilidades psicológicas, económicas y sociales, que modifican la estructura familiar, tanto durante el proceso como en la aceptación de la presencia o ausencia definitiva de quien se ha separado (García y Suarez, 2007). En investigaciones previas se ha demostrado cómo el poder tener acceso a ver el cadáver de un familiar desaparecido, disminuye la ambigüedad de la pérdida, aún y cuando la muerte se haya dado por circunstancias trágicas o de gran adversidad (Ortiz-Ruiz y RiveraHeredia, 2017).

El presente trabajo pretende mostrar un estudio de caso acerca del impacto que tiene la desaparición forzada de un integrante de una familia originaria del Estado de Michoacán (México). Se describe cómo es que la familia vivencia el duelo ante una perdida ambigua, además de cómo se perciben al ser víctimas de este suceso, en los ámbitos sociales, psicológicos, jurídicos y de salud.

El desarrollo del tema comienza por revisar los antecedentes históricos de la desaparición forzada; para finalmente describir el impacto emocional y social, a partir del análisis discursivo de las entrevistas que se realizaron con los distintos miembros de la familia.

\section{ANTECEDENTES HISTÓRICOS DE LA DESAPARICIÓN FORZADA EN MÉXICO}

El Comité de familiares de Detenidos Desaparecidos iHasta encontrarlos! En su "Informe sobre la situación de desaparición forzada en México ante la CIDH", elaborado por un grupo de comités y asociaciones civiles (2013), refiere que la desaparición forzada es una práctica que desde la década de los '60 se ejercía con planeación y sistematicidad. Menciona también que entre 1969 y 1988, durante la lucha del Estado mexicano en contra de movimientos insurgentes y organizaciones sociales, periodo conocido como "guerra sucia", fueron registrados entre 1200 y 1800 desapariciones forzadas por motivos políticos. Otra etapa 
donde se registra desapariciones forzadas es la que va de 1994 al 2000, a raíz de apariciones públicas de movimientos sociales armados. En el contexto actual de la desaparición forzada, desde el 2006 México vive un contexto marcado por la política de seguridad impulsada por el gobierno federal, la cual se expresa en la llamada "guerra contra el narcotráfico".

El informe antes mencionado señala que en Michoacán, México, fueron registradas 275 desapariciones forzadas de 2001 a mayo del 2012. En Nuevo León hasta el año 2012, son 202 casos que tiene registrados, en 57 de ellos tiene datos suficientes para afirmar que se trata de desapariciones forzadas de personas. En Guerrero, la Comisión Estatal de Defensa de los Derechos Humanos atendió más de 520 peticiones de apoyo en casos de víctimas de desaparición forzada del 2005 a principios del 2012. En Coahuila se encuentran documentados 258 casos desde el 2005 al 2012.

Camacho y Gómez (2012) en una publicación en el periódico "La Jornada" refieren que la Campaña nacional contra la desaparición forzada mencionan que: "México ha documentado 57 casos de defensores de derechos humanos que, desde el 2006 a la fecha, han sido víctimas de desaparición forzada" (p.14).

Como se puede apreciar la desaparición forzada es algo que ha existido desde tiempo atrás, sin embargo, la lucha para acabar con este tipo de prácticas no ha sido suficiente, pues a pesar de que ya ha sido tipificada en todos los estados de la República, la práctica de desapariciones forzadas sigue existiendo y en muchos casos permanece sin aclaración alguna, motivo por el cual familiares de los desaparecidos atraviesan por diversas situaciones ante la sociedad y la misma familia.

\section{IMPACTO EN LA DINÁMICA FAMILIAR}

Toda familia presenta una dinámica propia, la cual con el paso del tiempo se modifica con base en todos los factores que inciden en ella e incluso puede llegar a ser más evidente ante situaciones inesperadas como la muerte o la enfermedad repentina de un integrante. Concha y Hernández (2008) menciona que la pérdida de un ser querido constituye un cambio muy difícil que impacta a todo el sistema familiar fragmentando el equilibrio y las pautas establecidas de roles e interacción cambiando el presente y el futuro de cada uno de los miembros.

La dinámica familiar, de acuerdo con Camí (2009) se manifiesta a través de los vínculos que relacionan los diversos integrantes de una familia y se puede 
observar a través de emociones, comunicaciones, normas y roles, es decir a través de la interacción cotidiana entre los miembros de la familia. De acuerdo con esta autora, la comunicación se manifiesta no solo en palabras, sino también en gestos, posturas, silencios, olvidos, equivocaciones. En las relaciones familiares existe un componente afectivo, que al basarse predominantemente en lenguaje no verbal, genera la dificultad de traducir correctamente esa comunicación. Por otra parte, menciona que cada integrante de la familia realiza varios roles que integran a su estructura y se refiere a la totalidad de las expectativas y normas que una familia tiene con respecto a la posición y conducta de sus miembros. Un concepto ligado al de los roles es el del poder en la familia. Expresar las normas que tiene la familia es algo complicado ya que estas van cambiando de acuerdo al balance emocional de las necesidades de cada uno de los miembros y las de la familia como grupo.

La pérdida de un integrante, de acuerdo con Pérez y Graciano (2006), suele afectar de forma directa e indirecta tanto la estructura, como las dinámicas familiares, complicando también el estado emocional y fisiológico de los sujetos y es por ello que al existir una gran cantidad de estrés en los integrantes a causa de la pérdida o enfermedad de su ser amado puedan presentarse complicaciones orgánicas desde el punto de vista psico-corporal, como lo hace notar Borbeau (2012), la enfermedad podría brotar cuando los sujetos llegan al límite propio, ya que cada uno tiene un límite de energía física, mental y emocional diferente a los que le rodean.

\section{MÉTODO}

El artículo se basa en un estudio de caso, basado en el paradigma cualitativo, desde el enfoque fenomenológico, utilizando la técnica de la entrevista a profundidad. Se contó con la participación de una familia de Morelia, Michoacán, constituida por la madre, el padre, tres hermanas y una hija del individuo desaparecido.

A lo largo de las cinco entrevistas que se llevaron a cabo con la familia, se indagó acerca de la vivencia de cada integrante de la familia del individuo desaparecido, considerando cuatro dimensiones a estudiar: psicológica, jurídica, social y de salud. Dichas entrevistas fueron realizadas tres años después del hecho.

El procedimiento que se llevó a cabo, comenzó solicitando a la familia su autorización para participar en el proyecto de investigación, después de explicar- 
les los objetivos del estudio y las características de la técnica con la que se trabajaría. De esta manera, se contó con el consentimiento informado y se respetaron las consideraciones éticas partiendo de los principios de colaboración voluntaria y anónima, garantizando el uso exclusivo de los datos únicamente para fines académicos. Se solicitó a los participantes contestar cada cuestión de manera honesta y libre. Para concluir la entrevista, se le encomendó a la familia contar una anécdota basada en algún recuerdo agradable en su relación con el integrante ausente, intentando con esto, dejarles con ideas positivas después de re-avivar lo ocurrido. Los datos proporcionados durante las entrevistas, fueron grabados con el consentimiento de los participantes para posteriormente hacer el análisis. Asimismo, aunque ya había pasado tiempo del trágico suceso, se ofreció apoyo psicoterapéutico a la familia completa en las instalaciones del Centro Integral de Intervención Psicológica, perteneciente a la Facultad de Psicología de la Universidad Michoacana de San Nicolás de Hidalgo.

\section{RESULTADOS}

Este apartado, en investigación cualitativa equivale a los "hallazgos". En primer lugar, para contextualizar la situación se presenta el resumen de la situación que dio origen a la investigación, en segundo término, se describen las categorías, mismas que se van analizando con base en la teoría en que se fundamentan.

\section{Descripción de la situación}

La persona desaparecida es A.M.L., un hombre de 37 años, nacido en Morelia Michoacán y residente del mismo lugar; es el segundo varón de una familia de clase media- alta, en la cual también existen tres hermanas y un hermano. El actual desaparecido era casado y tenía únicamente una hija.

A.M.L. era abogado, y había ido a Boca del Río, Veracruz, como representante legal de un Químico Farmacobiólogo que tenía un asunto por solucionar en la PROFECO, ya que, según información brindada por la familia, sería en ese Estado donde se llevaría a cabo la audiencia el día 14 de septiembre del 2010. El desaparecido viajaba con cuatro personas más: un abogado, dos químicos y un técnico-químico, siendo ellos los implicados para llevar a cabo la diligencia antes mencionada. Después de varias horas de viaje y ya por la noche, se encontraban instalados en un hotel, haciendo unos escritos que presentarían al día siguiente 
los dos licenciados, cuando la administradora del hotel les llamó y les dijo que buscaban al dueño del carro rojo con placas de Michoacán. El dueño de dicho automóvil, el químico J.A. acompañado del Lic. A.M.L., bajó a la calle y ambos duraron aproximadamente media hora discutiendo con los policías, los cuales eran Policías Intermunicipales de Boca del Río y policías de la Unidad de Prevención de Robo de Autos (UPRA), que decían que "el carro estaba reportado como robado".

Pasada otra media hora aproximadamente les pidieron que subieran por sus otros compañeros; sin embargo, ante la negativa de los michoacanos, los mismos policías se dirigieron hasta las habitaciones para sacarlos; los separaron, y los subieron a diferentes carros: una patrulla, un auto particular y el carro de los michoacanos. Una vez que los coches en los que los transportaban habían avanzado una cuadra, les taparon la cara y se los llevaron. Sin embargo, no los llevaron a la procuraduría ni a una delegación. Pasado un rato, regresaron los mismos policías por las cosas de los cinco huéspedes y no se ha sabido más de ellos.

El día 16 de septiembre del año 2010, tres días después de que su concubina K.M.L. perdió contacto con él, la familia se enteró de que A.M.L. había desaparecido y levantó la denuncia el 17 de septiembre del año 2010 en Morelia Michoacán; además, se presentó una segunda denuncia el día 21 de septiembre del mismo año en Boca de Río, Veracruz. No obstante, durante los dos meses subsiguientes, la familia recibió una amenaza de muerte si buscaban a los michoacanos desparecidos. Pasados los meses, gracias a que la hermana de otro de los desaparecidos comenzó a buscar a su familiar, contactó a la concubina de A.M.L. para solicitar información sobre lo ocurrido. A partir de esto, localizaron a las parejas de las otras víctimas, para juntos investigar por su propia cuenta e incluso con familiares de uno de los desaparecidos que radicaban en Veracruz, cuestionando a posibles observadores de los hechos. Fue entonces cuando la familia se enteró del nombre del hotel donde se habían registrado y de cómo fueron extraídos, al igual de quienes se los habían llevado. Pasado un tiempo, la policía de Veracruz empezó a investigar el caso, tomando declaraciones de testigos; puesto que los familiares de los diversos desaparecidos ya habían hecho la denuncia por desaparición forzada. Después de un año de los hechos, se logró detener a los policías que se los llevaron y al hacer su declaración ellos confesaron haber sustraído a los michoacanos del hotel, además de golpearlos, taparles la cara y entregarlos a otros sujetos de los cuales no proporcionan el nombre. A pesar de tener detenidos a los agresores, hasta el día de hoy no se les ha podido juzgar por el delito de Desaparición 
Forzada o Detención-Desaparición, debido a que no estaba tipificada en México como delito (al menos no en todos los estados de la República), además de las contradicciones por parte del gobierno al momento de juzgarlos.

\section{Categorías de análisis}

A partir de las entrevistas realizadas con la familia del desaparecido, así como la observación cualitativa durante las sesiones, se construyeron las siguientes categorías, con el único fin de saber cómo es que la desaparición forzada de un integrante de la familia puede llegar a afectar diversos ámbitos, e incluso si lograron procesar el duelo y cómo lo vivieron. Para esto se requiere comprender que el duelo es un proceso dinámico, necesario para aceptar la pérdida, aprender a vivir sin el ser querido, para recuperar el interés por la vida y volver a disfrutar de la existencia

\section{Afrontamiento del duelo}

En tanto al proceso de duelo, debemos entender que es justamente eso, un proceso que demanda tiempo, esfuerzo y trabajo, además que puede variar en cada uno de los sujetos dependiendo de los vínculos afectivos que tenía con el ausente, y aunque algunos profesionales marcan un tiempo de dos años o un año para que este concluya, los implicados no siempre lo viven de esta manera. Una de las teóricas más reconocidas en el tema del "duelo", es Elizabeth Kübler-Ross (1969), quien, basada en un trabajo con pacientes en fase terminal, afirma que luego de la muerte se inicia con un proceso en el cual la gente debe lidiar con la pérdida.

Kübler-Ross en su libro On Death and Dying (1969) menciona 5 etapas y dice que los dolientes no necesariamente atravesarán por ellas en un orden prescrito, sino que se trata de un proceso de aprendizaje donde poco a poco se va comprendiendo que es posible vivir y lidiar con la pérdida, asimilando, que el ser amado ya no está.

En el caso del estudio, se pudieron apreciar varias de las etapas entre los integrantes de la familia. Algunos dieron muestras de encontrarse en la primera de las etapas, "la negación", donde existe un rechazo consciente o inconsciente de los hechos; se trata de, un mecanismo de defensa que busca amortiguar el shock que produce la realidad con la que se enfrenta el doliente. Los siguientes discursos lo evidencian: 
"Cuando me dieron la noticia de que no encontraban a mi papá, creí que era una broma o mentira y comencé a buscarlo en los siguiente días". (Hija, E1).

"Parecía que era mentira, no lográbamos entender lo que estaba pasando en ese momento, incluso por algunas horas no hacíamos nada más que solo pensar en A.M.L." (Hermana 1; 2, E1).

Otros, vivían la segunda etapa del duelo es "la ira", manifestada en enojo hacia el ser amado, hacia el doliente mismo, a familiares o amigos, incluso a personas extrañas u objetos inanimados. Es un resentimiento hacia la persona que se ha ido y con ello causado un dolor inmenso, pero este enojo se vive con culpa, haciendo sentir a la persona más enojada aun, como en el caso de las afirmaciones de algunos de los familiares:

"A veces la gente juzga a la familia que tiene un desaparecido, incluso nosotros quizá alguna vez lo hicimos diciendo que seguramente andaba metido en cosas indebidas y por eso le habían desaparecido" (Hermana 3, E2).

"El que aún nos faltaban tantas cosas por vivir y que no esté hoy es lo que más me duele. El haber pasado tan poco tiempo con él es una de las cosas que me han marcado" (Hija, E1).

"El no saber decir un te amo a tiempo, cuando lo sientes es un gran error que nosotros teníamos, desde que el desaparece siempre buscamos repetírnoslo entre familia" (Hermana 3, E2).

"El gobierno tiene la completa culpa de lo que se vive" (Hermana 1, E2).

"No hacen caso a las demandas, nos ignoran, no atienden los casos" (Padre, E5).

"No sé qué hayamos hecho mal que lo estamos pagando muy caro" (Madre E2).

La tercera etapa es la "negociación", la cual es una manera de afrontar la culpa y se entabla de forma imaginaria o real, con aquellos hacia los cuales se dirigió la ira. En esta familia no se ha hecho presente enteramente, pues durante esta etapa el doliente busca hacer un pacto con dios o el ser superior en que se cree para que el ser amado que falta regrese prometiendo un estilo de vida saludable o mejor. Sin embargo, podemos observarlo en el discurso siguiente:

"Desde que mi hermano desaparece, todos nos buscamos más desde temprano aunque sea con un mensaje de texto para saber cómo estamos, porque nunca sabemos cuándo será la última vez que nos veamos, sin embargo dios sabe porque hace las cosas" (Hermana 2, E3). 
"Yo diario rezo, pidiéndole a Dios por mi hijo, porque me lo regrese. Incluso he prometido hacer mandas si me lo trae de vuelta." (Madre, E2)

La cuarta etapa es la "depresión", donde se llega a sentir una tristeza, miedo, o incluso incertidumbre de lo próximo a venir. Ocasionalmente llega a ser un tanto exagerado, pero es parte del proceso, y es por ello que no puede considerarlo como una enfermedad mental, si no como una respuesta adecuada al proceso que se vivencia. Durante esta etapa el doliente puede sentirse agotado y sin ganas de levantarse de la cama pues para él es una tarea demasiado complicada debido a la situación que está viviendo, sin embargo, estos sentimientos muestran que el doliente ha comenzado a aceptar la situación. Durante este proceso de duelo en la familia M.L. la única persona que presentó síntomas de depresión es la hija del desaparecido y se puede evidenciar en el discurso siguiente:

"Hubo unos meses en que solo me levantaba por inercia, no eran tantas mis ganas de seguir estudiando y hacer otras actividades; pero prácticamente me levantaba obligada por las circunstancias... Fueron meses muy largos para mí en los que solo lloraba y no salía de mi habitación, no tenía hambre y en ese momento sentía que el mundo se venía abajo" (Hija, E5).

La quinta y última etapa del proceso de duelo es la "aceptación". Durante esta se acepta la realidad de que el ser amado se ha ido físicamente y se comienza a formar una nueva realidad en la cual él no está presente, pero el doliente puede salir adelante. Es un proceso en el cual se aprende a convivir con la pérdida y se crece a través del conocimiento de nuestros sentimientos. Se puede decir entonces que una persona que regresa a sus diversas actividades y es funcional nuevamente ante ellas es una persona que ha superado exitosamente su duelo.

Sin embargo, al hablar de una desaparición forzada, muy difícilmente se puede esperar un cierre de cada una de las etapas, por eso es importante abordar el manejo de duelo ante una pérdida ambigua.

\section{Distintos tipos de duelo vivido.}

Existen diversos tipos de duelo por eso es importante explicar en cuales se encuentran la familia M.L, pues a pesar de que atraviesan por una perdida ambigua presentan diferentes tipos de duelos. Una pérdida ambigua se puede experimentar de varias maneras; de acuerdo con Ramos (2013) puede vivirse como un duelo colectivo cuando es experimentado por varias personas que comparten sentimientos similares al mismo tiempo; como duelo crónico cuando se arrastra por 
años, y va unido a la desesperación y como duelo congelado o retardado, caracterizado porque los sujetos, en los primeros momentos del suceso, no muestran dolor o afectación alguna ante la muerte de un ser querido. En el caso de esta familia se aprecian los tres, mismos que se describen a continuación.

El duelo colectivo, se manifiesta en que comparten sentimientos similares como el miedo a mencionar el nombre del integrante desaparecido y la desesperación por saber si se alimenta, si se encuentra bien, arrastrando el dolor y la desesperación que sienten los padres al pensar que él regresará. Se aprecia cuando la familia M.L. refiere que:

"No podíamos a veces ni comer, nos preguntábamos yo estoy comiendo, pero iy él? Mientras yo tomo agua a lo mejor a él ni siquiera le dan. Son tantas situaciones emocionales en un momento así, que pasa mucho tiempo para poder sentarte a comer a gusto". (Hermana 1, E2)

"Nuestra lucha no va a parar hasta encontrarlo, como sea que él se encuentre". (Hermana 3, E2).

"nos costó trabajo tomar decisiones". (Hermana 1, E2)

"sino hubiera tenido mendo tal vez hubiese hecho algo más". (Hermana 2, E2)

"creo en estos momentos de que pasa esto sientes tanto miedo que no logras tomar decisiones", (Hermana 3, E2)

Como se puede observar en los discursos de los participantes, se denota una pérdida ambigua (Boss, 2001; López-Peñaloza y Pintor Sánchez, 2018), muchas veces interminable y siempre desconcertante, las personas están proclives a la ansiedad y depresión, además de presentar conflictos en sus diversas relaciones.

La pérdida ambigua, puede deberse a la desaparición de una persona por cualquier situación violenta o tragedias naturales, incluso se puede experimentar cuando la persona ha sufrido cambios debido a enfermedades como el Alzheimer, traumatismo cerebral o un trastorno mental crónico.

Según Ruiz (2013) los síntomas que se presentan en este tipo de pérdida son similares a los del estrés postraumático, pues existe la presencia de ansiedad, depresión, sueños angustiosos, enfermedades psicosomáticas e incluso parálisis psicológicas y lo único que marcará la diferencia es el trauma, aquí referido como ambigüedad, el cual se alarga indefinidamente, alternándose entre la esperanza y la desesperación. 
"Nos vemos más cansados y demacrados, incluso notan que en las cuestiones de trabajo o actividades diarias se ven más distraídos y no dan el ancho". (Hermana 1, E2)

"Hay presencia de ansiedad, diagnosticada por los médicos" (Hermana 2, E5)

"Yo no quería hacer nada, no tenía ánimos de nada, además de que no me dejaban llorar en casa; solo asistía a la escuela, pero me aislaba de todo y todos”. (Hija, E2)

Por otra parte, la incertidumbre hace a las personas más vulnerables a reaccionar ante ciertas situaciones de maneras impredecibles, impidiendo con ello que los sujetos organicen nuevamente las normas o papeles de las relaciones con sus seres allegados, y por ende llega a suceder que los que la padecen se aíslen en las diferentes áreas en las que se desempeñan o con las diversas relaciones que puedan llegar a tener. El duelo crónico, manifestado a través de una melancolía patológica también se hace presente en esta familia en el caso de la madre cuando la hija del desaparecido menciona:

"Mi abuela, desde que desaparece mi papá, se la pasa sentada frente a la puerta con la esperanza de que un día regrese". (Hija, E2)

Esta melancolía es donde el sujeto permanece con una fijación, típica del duelo crónico caracterizado por tener una duración descomunal y nunca podrá llegar a una conclusión satisfactoria (Ramos, 2013). La madre suele sentarse frente a la puerta esperando que algún día entre de nuevo a casa, pues ella cree que su hijo está vivo. De este modo lo mantiene presente psicológicamente a pesar de su ausencia física. Como se puede apreciar en los discursos, la pérdida ambigua, a diferencia de la muerte, ocasiona que los sujetos que la viven no logren el desapego necesario para una culminación normal de su duelo, ya que la confusión hace el proceso aún más difícil.

También se observa el duelo congelado o retardado, en el caso de la hija del desaparecido, ya que a un principio ella no mostraba sentimiento alguno, puesto que no creía lo que sucedió, Cuando este tipo de duelo no se resuelve, puede afectar a la descendencia a lo largo de las generaciones siguientes y agravarse a lo largo del tiempo, como lo plantea Tisseron (1997) al hablar de la transgeneracionalidad, donde especifica que el funcionamiento psíquico del individuo no solo se relacionará con los conflictos propios y experiencias particulares, por el contrario, también influirán para ello las vivencias y accidentes que hayan marcado la vida de los padres, abuelos o amigos cercanos. Por lo tanto, es importante atender el trauma desde la primera generación hasta las siguientes, para que se logre aprender totalmente como sobrellevar el suceso, en caso de que no llegara a una culminación. 


\section{Malestares orgánicos}

El pasar por algún tipo de pérdida puede desencadenar síntomas ya sean físicos, emocionales o cognitivos, algunos de estos son ansiedad, dolores de cabeza, achaques, irritabilidad, falta de descanso, alteraciones del sueño, trastornos alimenticios, frustración, sentimientos de vulnerabilidad, de abandono, de impotencia, rabia, ira, miedo, temores, desorientación, dificultad para concentrarse o tomar decisiones, sensación de que el mundo es irreal (García y Suárez, 2007).

Ahora bien, según Bourbeau (2012), el cuerpo es el reflejo de lo que acontece en nuestro mundo psíquico y por lo tanto, lo que un cuerpo enfermo busca es restablecer el equilibrio, ya que su estado natural es la salud. Además, que las causas más comunes para las enfermedades son las emociones o actitudes negativas, la búsqueda de atención, la culpabilidad y la utilización de una enfermedad para evitar situaciones desagradables o huir de ellas, como lo menciona:

"Yo siento que ahora quizá por la situación que atravesamos, mi esposa de pronto hay temporadas en que se pone de un humor muy malo, aunque poco a poco ha ido disminuyendo la tensión (Padre, E5).

Con respecto de la salud de la familia, se dio a conocer que antes de este hecho nadie presentaba ningún síntoma de enfermedad, mientras que después de la desaparición, comienzan a brotar ciertos síntomas que hacen a los familiares acudir al médico. Ellos también refieren que hay un cambio evidente físico, un desgaste emocional, un juego de emociones y sentimientos incontrolables e inexpresables, según mencionan:

"Antes ninguna, pero yo ahora la diabetes" (Madre, E5)

"Yo de los riñones" (Hermana 1, E5)

"Yo de los bronquios" (Hermana 3, E5)

"A míse bajan las defensas y me enfermo más de gripa y tos" (Hermana 2, E5)

"A míme da más seguido gripa y tos" (Padre, E5)

"Nos notamos más cansados, y nos hemos acabado, nos vemos más demacrados" (Madre, E5)

"Se ven más desgastados mis tíos y abuelos, mi abuela subió mucho de peso porque ya no sale ni a la esquina, solo se la pasa sentada, mi abuelo se ve más cansado, y todos padecen de sueño" (Hija, E5) 
Como se puede observar los integrantes de esta familia presentan algunos de los síntomas mencionados por García y Suárez (2007) como el cansancio en los padres, el desgaste físico en los hermanos, la irritabilidad de la madre por no saber nada de su hijo, el miedo, el temor de mencionar lo sucedido, dificultades para la toma de las decisiones, la sensación de que lo vivido no es real. La somatización de la angustia y temor poco a poco han salido en forma de enfermedades, al principio de la desaparición de A.M.L. algunos integrantes comenzaron con diabetes, bronquios y tener defensas bajas. Después de un tiempo salieron a flote otras enfermedades como problemas cardiacos y estomacales; la persona que tuvo cambios más drásticos es M. pues ella deja de caminar por dolor en una rodilla que hasta la fecha aún persiste, esta información se obtuvo por medio de la hija de A. y por observación.

\section{Estrategias familiares de recuperación}

Dadas las características de toda dinámica familiar, esta nunca permanecerá estática ante las diversas situaciones que se puedan presentar, puesto que basta con que alguno de los miembros genere algún cambio relevante en su conducta o en sus interacciones, para que toda la familia se vea afectada positiva o negativamente por tal cambio. En el caso de la pérdida de un integrante, como refieren Pérez y Graciano (2006) puede afectar de forma directa e indirecta las dinámicas familiares complicando también el estado emocional y fisiológico de los sujetos en cuanto a su entorno familiar, es decir, implica un proceso de adaptación. El impacto de la desaparición a que se alude en este artículo, se aprecia en los discursos siguientes:

"No te terminas de adaptar, sobrellevas tu vida, pero nunca te adaptas a la parte que te falta" (Hermana 3, E4)

Cabe mencionar que a pesar de esta ambigüedad en muchas ocasiones los integrantes de la familia pueden crear ciertos rituales que les ayudan a elaborar el duelo y con ello desarrollar más herramientas para poder continuar su vida. Arreola, Contreras y Gómez (2016) hacen referencia a que dentro de las familias que enfrentan una pérdida de esta índole, la fe religiosa se presenta como una fortaleza que les ayuda a seguir adelante y que en ocasiones esta misma fe ayuda a los individuos a sobre llevar las situaciones y enfrentar la pérdida, ya que la religión y espiritualidad podrán ser factores que brinden apoyo al sujeto para dotar de sentido de trascendencia su vida. Algunas integrantes de la familia, utilizaban este recurso para afrontar la situación, como se evidencia en los discursos: 
"Hasta cierto punto me siento tranquila, ya que en casa se le hizo un novenario y eso me ayuda a entender que él no regresara y yo debo continuar con mi vida". (Hija, E2)

"Creo que la fe no se pierde, hasta saber algo de él" (Hermana 2, E 4)

"Yo siempre rezo con el fin de pedirle a nuestro señor que nos permita volver a saber de mi hijo" (Madre, E5)

Estas y otras prácticas permiten que paulatinamente se vaya elaborando el duelo y, a partir de ahí, construir o reconstruir un sentido de vida, como destaca Frankl (1994): "Las dificultades cuando más grandes sean, acentúan el carácter de deber, que tiene nuestra existencia y con ello se da más sentido a la vida (p.15)". En este caso, tal y como se explica el sentido de sufrimiento desde la perspectiva de Frankl (1991), aun en el dolor y el sufrimiento, y justo cuando se considera tener lejos una meta, la elección de actitud permanecerá abierta, ya que como seres humanos tenemos la capacidad incluso de asumir el sufrimiento como parte de trascender y con ello permitir alejarnos del dolor, para así encontrarle sentido a cualquier experiencia que se presente.

Ahora bien, las familias evolucionan y experimentan procesos diversos en los que deberán modificarse desde su dinámica y el cambio de rol, para que lograr adaptarse a las nuevas condiciones, aunque no siempre resulta lo más adecuado, como lo expresan algunos participantes:

"Yo creo que entre todos agarramos el de protección, protegernos a todos de una u otra manera. Quizá no vengo a casa pero estoy pendiente de ti, no nos hablamos pero aun así indirectamente le pregunto a otro como están" (Hermana 3, E4)

"Creo que todos mis tíos se preocupaban por todos al igual que mis primos siempre se estaban llamando para saber cómo estaban, o incluso se iban a buscar para cerciorarse de que estaban bien, se abrazaban más frecuentemente, al menos cuando se visitaban y nos mandábamos o se mandaban mensajes de te quiero o te amo" (Hija, E4)

"Creo que no se han cambiado, aunque bueno se cambian algunas situaciones, yo en lo personal vivo con mucho miedo, tengo dos hijos y yo sé que no los puedo ahogar con estarlos cuidando. Pero sí se toma una actitud de sobreprotección con la hija de mi hermano, porque en el momento en que él desaparece, su hija vive aquí con mis papás y se siente el compromiso o responsabilidad de cuidar a su hija, aún más que a los demás, para que no le pase nada por lo que ya nosotros venimos arrastrando. Antes tenía uno que la regañaba y ahora somos cuatro" (Hermana 1, E4)

“Tomamos el papel de papás hacia todos" (Hermana 2, E4) 
"Todos se volvieron papás de todos, se perdieron rangos y respeto, porque ahora todos se regañan y llaman la atención" (Hija, E4)

"Aquí ya no hay grados de sobrinos, tíos, ahora todos somos papás de todos" (Hermana 3, E4).

"Ninguno cambia, solo que ahora todos son papás de todos los sobrinos y en especial de la hija de mi hermano" (Hermana 3, E4)

"Empezaron a ser demasiado sobreprotectores y más conmigo" (Hija, E4)

Como se observa en la familia M.L, cada integrante realiza varios roles que son integrados a su estructura, normas y totalidad de las expectativas que la familia tiene con relación al estado emocional y comportamiento de cada uno de sus miembros (Camí, 2009). Una parte primordial al analizar un caso como este es observar la modificación que ocurre con el paso del tiempo o incluso desde el momento de la desaparición, ya que la estructura de la familia suele ser cambiada como se apreció en los discursos de la familia M.L. que de tener una estructura familiar aislada se reestructuró como una familia aglutinada, según las categorías presentadas por Aronne (2007).

Con respecto de los procesos comunicativos, la familia M.L. atravesó por diversas situaciones dentro de este proceso, como ellos lo refieren

"Antes, no nos juntábamos tanto, solo ocasionalmente nos juntábamos los hermanos a comer los domingos y días festivos. Hoy, después de cuatro años nos juntamos más, aunque ya no es igual sin él, y sin embargo desde un tiempo hacia acá no podemos por compromisos personales" (Hermana 1, E4)

"A mí me molestaba mucho que le lloraran tanto a mi papá si nunca lo habían procurado y la relación entre ellos estaba más que rota. Sin embargo, su familia empezó a reunirse un poco más, se llamaban más por teléfono, o incluso se visitaban” (Hija, E4)

"Bueno yo considero que antes de que desapareciera sí estábamos unidos, pero quizá no al grado de como lo estamos ahora" (Hermana 3, E4)

"Yo creo que antes de ser desaparecido, sí nos uníamos, pero no tanto; cuando se da este suceso, nos unimos exageradamente, pero de un tiempo para acá creo que la desunión se ha vuelto a dar en la familia, por diferencias o por lo que sea" (Hermana 1, E4)

De acuerdo con los autores mencionados se determina que la familia M.L. ha experimentado cambios muy notables a partir de la muerte de A.M.L. pues como ellos comentan es algo que se tiene que sobrellevar nunca se termina de 
adaptar a la pérdida de un ser querido, los cambios que experimenta esta familia se centran en la unión al momento que se enteran de la desaparición de uno de sus miembros, demostrándose afecto físico y emocional además de una mayor comunicación, e intentando protegerse unos a otros y sobreprotegiendo a la hija de quien desaparece, adaptando cada integrante diferentes roles a partir de la reestructura familiar después de la pérdida ambigua que vivencia.

\section{Afrontamiento de la falta de apoyo legal por parte de la familia}

La manera en que la familia afrontó el proceso legal, también aumentó la angustia y generó frustración e indignación, puesto que poco o nada se respetaron las recomendaciones ante la desaparición de un familiar que brinda el "Manual de acciones frente a la desaparición y la desaparición forzada; orientaciones para las familias mexicanas de personas desaparecidas" (González y colaboradores, 2016). Entre los datos más relevantes, destacan los que se describen en seguida.

En el manual se pide que inmediatamente se levante una denuncia ante las autoridades correspondientes, exigiendo los derechos correspondientes: que realicen la búsqueda del familiar desaparecido y para que comiencen a llevar a cabo las diligencias que permitan identificar a todas las personas que hayan participado en la desaparición. Sin embargo, la familia se encontró con respuestas negativas desde el momento que hacen la primera denuncia tres días de perder comunicación con él, el 16 de septiembre del año 2010, en Morelia Michoacán, como ellos mencionan en el proceso, la reacción de las autoridades ante el caso fue:

"De indiferencia" (Hermana1, E 4)

"Despotismo" (Hermana 1, E4)

"Intimidación a la familia" (Hermana 2, E4)

Es importante mencionar que, desde el punto de vista legal, el Ministerio Público no puede negarse a levantar la denuncia, y tampoco puede pedir que se espere un tiempo determinado, ya que al hacerlo incurren en una violación de la ley. Al enfrentarse a la negativa de las autoridades, la familia empezó a buscar pistas hasta encontrar a los familiares de las personas que acompañaban a A.M.L., comenzando a dialogar sobre los hechos y trabajando en conjunto se unieron a la asociación de búsqueda "Hasta encontrarlos".

"Se levanta una denuncia en la procuraduría por desaparición. Luego nosotros no sabíamos con quién se había ido, así que empezamos a buscar pistas y nos encontramos con familiares de los que iban con mi hermano y empezamos a dialogar sobre los 
hechos y a trabajar en conjunto unos con otros, luego nos unimos a algunas asociaciones de búsqueda como la de "Hasta encontrarlos". (Hermana1, E3)

"Te presentas a levantar la denuncia por desaparición y te dicen -debe esperar mínimo 72 horas para que proceda, igual y anda borracho-". (Hija, E4)

"Mandan intimidar a las familias, de hecho las autoridades les decían cuando levantaron la primer denuncia que de seguro el desaparecido andaba de borracho o mujeriego que ni se preocupara, después cuando se levanta una segunda denuncia en Boca del Rio, las autoridades les dicen que si los de Veracruz piden ayuda lo buscan y los de Michoacán dicen lo mismo" (Hermana 1, E4)

Sin embargo, la familia no tiene el apoyo que requieren y que deben brindar las autoridades:

Entrevistadora: iLegalmente quéapoyo ha recibido la familia?

Respuestas de los familiares:

"Ninguno. Ni siquiera le han dado un seguimiento al caso, por otra parte en la secretaria de educación pública (SEP) que era donde él trabajaba tampoco nos brindaron apoyo y perdimos su plaza" (Hermana 1,E4)

"Nunca nos quisieron atender" (Hermana 3, E4)

"Nunca nos apoyaron" (Hermana 2, E4)

"Nunca nos escucharon" (Madre, E4)

Pasado un tiempo, los familiares realizaron una segunda denuncia el día 21 de septiembre del año 2010 en Boca del Rio; Veracruz, lugar donde A.M.L., desapareció. En esta ocasión, las autoridades procedieron con la denuncia, sin embargo, no la realizaron como se debe, ya que no se ejecutaron los procedimientos legales correspondientes, algunos de estos se mencionan en el aludido Manual de acciones frente a la desaparición y la desaparición forzada...: En dicho manual, se indica que el Ministerio Público tiene el deber de efectuar, conforme a su protocolo homologado para la investigación del delito de desaparición forzada, por lo menos las siguientes acciones inmediatas:

- Emitir una alerta a la red nacional de búsqueda de personas desaparecidas.

- Realizar una entrevista (cuestionario Ante Mortem) para profundizar en la información sobre el familiar desaparecido. Dentro de esta entrevista las autoridades tienen que recabar muestras de $\mathrm{ADN}$ de los padres biológicos o de un hijo. 
- Inspeccionar el último lugar en el que se ubicó a la victima de desaparición. Debe realizar entrevistas a compañeros de trabajo, amistades, o posibles testigos.

- Solicitar a la empresa correspondiente la entrega de registros telefónicos de la persona desaparecida.

Al finalizar los procedimientos de la denuncia, el Ministerio pide a los familiares que se firme, pero antes de hacerlo, los familiares que pusieron la demanda deben de asegurarse que todo sea tal como ellos indicaron. En el caso de la familia M.L., estos pasos no se llevaron conforme a la ley, pues no se les tomaron muestras de $\mathrm{ADN}$ al realizar la denuncia, ni la respuesta de las autoridades tanto de Morelia como de Veracruz, fue la adecuada. Por estos motivos, la familia está insatisfecha con los resultados legales obtenidos, como ellos mismos lo refieren:

En la procuraduría nos decían "pues si Veracruz pide apoyo, nosotros lo brindamos, y sino, pues no podemos entrar asínada más a su estado". Y en la procuraduría de Veracruz nos decían lo mismo, que si Michoacán pedía apoyo se le brindaba y sino pues no podían hacernada. El chiste es que ni uno ni otro hicieron algo. (Hermana 1, entrevista 4)

\section{DISCUSIÓN}

Después de realizar esta investigación se puede apreciar que la desaparición de un integrante en la familia dificulta el proceso de la conclusión de un duelo, como en el caso de la familia M.L. que experimenta una pérdida ambigua, ya que al no saber el paradero de A.M.L., viven en constante incertidumbre haciéndolos más vulnerables ante ciertas circunstancias, llevando consigo un profundo dolor y desesperación tratando de encontrar a su familiar. La manera en que la familia afrontó el proceso legal, también aumentó la angustia y generó frustración e indignación puesto que no encontraron la respuesta esperada, enfrentándose a una negativa tanto de autoridades de Morelia como de Veracruz.

Como se menciona en los hallazgos, los roles que cada integrante de esta familia tenía antes de enfrentase a este suceso, se modificaron por completo después de vivir este proceso, asumiendo una actitud de sobreprotección hacia cada integrante y más aún hacia la hija del desaparecido, manteniendo una relación más cercana, pues después del hecho se vuelven más unidos; sin embargo, después de un tiempo, comenzó de nuevo el desapego familiar y es más notable que antes. 
Ahora bien, cuando una familia atraviesa por un duelo de este tipo, no solo cambia su dinámica sino su estructura en general, afectando también su estado de salud, pues al somatizar la angustia por no saber de su familiar, de algún modo tendrá que manifestarse el temor vivenciado y éste, con frecuencia, tal como lo plantea Bourbeau (2012), se expresa a través de enfermedades.

Es importante comprender que, a pesar de la existencia de las cinco etapas de un duelo planteadas por Kübler-Ross (1969), no es forzoso el pasar por cada una de ellas, pues como se observó cada integrante está situado en etapas completamente diferentes afrontando de distinta manera su duelo. Así como cada uno se encuentra en un tipo de duelo diferente, pues no todos han experimentado de la misma forma el duelo.

Parte fundamental para que la familia logre salir de este proceso es que comprendan que la dinámica familiar está en continuo movimiento que se intensifica en ciertas situaciones como por la que ellos atraviesan, y que pueden encontrar rituales para aceptar la situación, pero sobre todo necesitan comprender que los cambios en estos procesos son necesarios para recuperar un óptimo funcionamiento.

Es un desafío muy grande el lograr que las familias que experimentan estas situaciones cambien la percepción de la ausencia o presencia de su familiar ya que en muchos casos no han comprobado su muerte y siguen manteniendo la esperanza de encontrar con vida a la persona desaparecida.

Es necesario que casos como este se den a conocer, para que las personas que estén pasando por una situación similar estén enterados de que no son los únicos, y que existen fundaciones que pueden ayudarlos tanto de manera emocional como legal. También es importante que conozcan los derechos que tienen y que el ministerio público no puede negarles el apoyo legal de ninguna manera.

En la actualidad existen muchos casos sobre esta índole, por lo que es importante que se brinde una atención a las víctimas, lo más pronto posible, ya que, al atravesar por la vivencia de la desaparición forzada de un integrante de la familia, hay un impacto psicosocial, que se refleja en afectaciones a la estabilidad de las personas, alterando su sentido de vida, sus relaciones interpersonales, conyugales, familiares, así como en su ámbito laboral y social. Por tal motivo, es sustancial mencionar la importancia de la intervención desde la psicológica clínica, trabajando la resiliencia, a partir de los recursos psicológicos de los individuos involucrados en dicho proceso (Ramírez-Baeza y Rivera-Heredia, 2018), así como encontrando un nuevo sentido de vida para poder concluir el duelo. 


\section{REFERENCIAS BIBLIOGRÁFICAS}

Aronne, E. (12 Noviembre, 2007). La familia: concepto, tipos, crisis, terapia. [Entrada de blog]. Recuperado de http://www.evangelinaaronne.com.ar/2007/11/la-familia-concepto-tiposcrisis.html

Arreola, C., Contreras, M., Gómez del Campo, M., (Junio, 2016) Efectos de la intervención logoterapéutica con padres de hijos desaparecidos. El caso de San Miguel Totolapan. (México). Anfora, 23(40), 99-120. Universidad Autónoma de Manizales.

Recuperado de http://www.redalyc.org/articulo.oa?id=357846226004

Borbeau, L., (2012) Obedece a tu cuerpo. Argentina: Sirio.

Boss, P., (2001). La pérdida ambigua. Barcelona, España: Gedisa.

Camacho, F., Gómez, C., (31 de agosto de 2012). Exigen ONU, AI y CIDH fin de las desapariciones forzadas en México. La Jornada, p. 14

Camí, A. (2009). Introducción al trabajo familiar en casos de vulnerabilidad. (Tesis de maestría, Córdoba: Coordinadora Estatal Plataformas Sociales Salesianas). Recuperado de http://psocialecp50.wordpresstemporal.com/wp-content/uploads/2017/09/01-Trabajo-Familiar.pdf

Concha, D., Hernández, J., (2008). Duelo parental y cambios en el sistema familiar (Tesis de licenciatura, Universidad Academia de Humanismo Cristiano: Escuela de trabajo social. SantiagoChile) Recuperado de

http://bibliotecadigital.academia.cl/bitstream/handle/123456789/1607/ttraso244.pdf?sequ ence $=1$ \&isAllowed $=\mathrm{y}$

España: La pérdida ambigua, Aceptando la incertidumbre (Mayo, 2013). Ruíz, María C. [Entrada de blog]. Recuperado de https://mariaclararuiz.com/2013/05/28/la-perdida-ambiguaaceptando-la-incertidumbre/

Fernández, D., Téllez, A., Reyna, P., González, D., Elizalde, E., González, A y Salcedo, (2016). Manual de acciones frente a la desaparición y la desaparición forzada. Orientaciones para las familias mexicanas de personas desaparecidas. México: Universidad Iberoamericana. Recuperado de http://www.somoselmedio.org/article/manual-de-acciones-frente-ladesaparici\%C3\%B3n-y-la-desaparici\%C3\%B3n-forzada

Frankl, V. (1991) El hombre en busca del sentido. México: Herder.

Frankl, V. (1994) La voluntad de sentido. Barcelona: Herder.

García L., Rosa I., Suárez M., (2007) La pérdida ambigua: una prolongada aflicción de la familia. Psicología y Ciencia Social, 9(2), 32-41. Universidad Nacional Autónoma de México. Recuperado de http://www.redalyc.org/pdf/314/31414787004.pdf

Informe sobre la situación de desaparición forzada en México ante la CIDH. (Abril, 2013) iHasta encontrarlos! Comité de familiares de Detenidos Desaparecidos. (3) p.11. Recuperado de http://hastaencontrarlos.org/spip.php?article952

López-Peñaloza, J. y Pintor-Sánchez, B. (2018). Violencia y Duelo ambiguo en México. El caso de los desaparecidos y sus familias (47-64). En O. Esparza Del Villar, P. Montañez, I. Carrillo y M. Gutiérrez (coords). Fenómenos de la Violencia en México y su repercusión psicológica en la población. Ciudad Juárez: Universidad Autónoma de Ciudad Juárez. 
Kübler-Ross E. (1969) On Death and Dying. New York: Macmillan.

México: Crisis de desapariciones forzadas. (Febrero, 2013). Human Rights Watch [Entrada de blog]. Recuperado de https://www.hrw.org/es/news/2013/02/20/mexico-\%20crisis-de$\% 20$ desapariciones-forzadas

ONU (2006). Convención Internacional para la protección de todas las personas contra las desapariciones forzadas. Recuperado de http://www.ohchr.org/SP/ProfessionalInterest/Pages/ConventionCED.aspx

Ortiz-Ruiz, J.C. y Rivera-Heredia, M.E. (2018). Regresar a la tierra de origen, aunque solo sean sus restos. Experiencias de familias que solicitan la repatriación de los migrantes que fallecen en EE.UU. En Reflexiones y Retos sobre la salud de la población migrante. (167-173). Ciudad de México: SEGOB/CONAPO e Iniciativa de salud de las Américas. Recuperado de https://www.gob.mx/cms/uploads/attachment/file/390663/Migraci_n_y_salud_2017_web_ final1.pdf

Pérez, S., Graciano, L., (2006) La dinámica familiar afectada por la muerte violenta de alguno de sus miembros (Tesis de maestría, Corporación Universitaria Minuto de Dios Facultad de Ciencias Humanas y Sociales). Recuperada de

http://repository.uniminuto.edu:8080/xmlui/bitstream/handle/10656/5004/TTS_PerezRest repoSandraJannet_2016.pdf? sequence $=1$ \&isAllowed $=y$

Procuraduría General de la República (2015). Información estadística sobre la desaparición de personas. Recuperado de www.pgr.gob.mx/Transparencia/Paginas/desaparicion-personas

Ramírez-Baeza, R. y Rivera-Heredia, M.E. (2018). Crecer ante la adversidad de la violencia en el entorno. Segunda parte: resiliencia y recursos psicológicos. En O. Esparza Del Villar, P. Montañez, I. Carrillo y M. Gutiérrez (coords). Fenómenos de la Violencia en México y su repercusión psicológica en la población. (197-226). Ciudad Juárez: Universidad Autónoma de Ciudad Juárez.

Ramos, Ma. Del C. (2013) Duelo ante una muerte inesperada (Tesina de diplomado, Asociación Mexicana de Tanatología, A.C. México D.F.) Recuperado de http://www.tanatologiaamtac.com/descargas/tesinas/200\%20duelo.pdf

Rodríquez M. (s.f.). Entra en vigor ley de Desaparición Forzada. Canal judicial. Recuperado de https://canaljudicial.mx/es/noticia/entra-en-vigor-ley-de-desaparicion-forzada

Tisseron, S. (1997). El psiquismo ante la prueba de las generaciones. Buenos Aires: Amorrortu. 